\title{
Doping and Respiratory System
}

\author{
L. Casali1, G. Pinchi2, E. Puxeddu1
}

ABSTRACT: Doping and Respiratory System. L. Casali, G. Pinchi, E. Puxeddu.

Historically many different drugs have been used to enhance sporting performances. The magic elixir is still elusive and the drugs are still used despite the heavy adverse effects.

The respiratory system is regularly involved in this research probably because of its central location in the body with several connections to the cardiovascular system. Moreover people are aware that $\mathrm{O}_{2}$ consumption and its delivery to mitochondria firstly depend on ventilation and on the respiratory exchanges.

The second step consists in the tendency to increase $\mathrm{V}^{\prime} \mathrm{O}_{2} \mathrm{max}$ and to prolong its availability with the aim of improving the endurance time and to relieve the fatigue.

Many methods and substances had been used in order to gain an artificial success.

Additional oxygen, autologous and homologous transfusion and erithropoietin, mainly the synthetic type, have been administered with the aim of increasing the amount of oxygen being delivered to the tissues.

Some compounds like stimulants and caffeine are endowed of excitatory activity on the CNS and stimulate pulmonary ventilation. They did not prove to have any real activity in supporting the athletic performances.

Beta-adrenergic drugs, particularly clenbuterol, when administered orally or parentherally develop a clear illicit activity on the myosin fibres and on the muscles as a whole.

Salbutamol, terbutaline, salmeterol and formoterol are legally admitted when administrated by MDI in the treatment of asthma.

The prevalence of asthma and bronchial hyperactivity is higher in athletes than amongst the general population. This implies that clear rules must be provided to set a correct diagnosis of asthma in the athletes and a correct therapy to align with the actual guidelines according to the same rights of the "other" asthmatic patients. Monaldi Arch Chest Dis 2007; 67: 1, 53-62.

Keywords: Doping, beta-2 stimulants, clembuterol, caffeine, ephedrine, anabolic steroids, erythropoietin.

${ }^{1}$ Department of Internal Medicine, Section of Respiratory Disease, University of Perugia and Postgraduate School of Sports Medicine, University of Perugia,

2 Clinical Respiratory Physiology Service, Azienda Ospedaliera S. Maria, Terni - Italy.

Correspondence: Prof. Lucio Casali, Dipartimento di Medicina Interna, Sezione di Malattie Respiratorie, Università degli Studi di Perugia - UC Mal. App. Resp. Az. Ospedaliera "Santa Maria” di Terni, via Tristano di Joannuccio 1, 05100 Terni, Italy; e-mail: lcasali@unipg.it

The English noun "doping" and the similar verb "to dope" share a general and unvarying sense all over the world indicating the assumption of prohibited substances in order to obtain better performances in many sports. The athletes who use these substances are defined to be "under drugs" independently of the kind of a specific drug and of the aim of its assumption.

The origin of the term "doping" has perhaps to be researched in the custom of some African people, i.e. the Cafiri, who defined "dop" an alcoholic extract endowed of exciting properties they used to drink during their religious ceremonies.

Doping now is a malpractice connected to many sports and physical activities, both professional and recreational and according to IOC and to WADA code consists of the administration of substances belonging to prohibited classes of pharmacological agents and the use of various prohibited methods [1-2]. The 2006 prohibited list established by WADA [2] and the consequent world anti-doping code enumerates the substances and methods prohibited at all times in and out of competition and the use of any drug should be limited to medical justified indications. Subdividing the list of substances into chapters the following categories must be quoted (tab. 1):

Looking at the different categories we can briefly provide detail as follows:

S1 Anabolic agents: Anabolic Androgenic Steroids (AAS): exogenous (substances which are not ordinarily capable of being produced by the body naturally) and endogenous (substances capable of being produced by the body naturally). All the anabolic agents are prohibited.

Other anabolic agents: among them bronchodynamic agents such as clenbuterol have been included.

\section{S2 Hormones and related substances}

S3 Beta-2 agonists: all beta- 2 agonists including their $\mathrm{D}$ and L-isomers are prohibited with the exception of formoterol, salbutamol, salmeterol, terbutalin only when administered by inhalation and after a proper certification is provided. A concentration of salbutamol greater than $1000 \mathrm{ng} / \mathrm{ml}$ is however considered an Adverse Analytical Finding unless the athlete proves that the abnormal result was the consequence of a mandatory therapeutic use of inhaled salbutamol. 
Table 1. - List of prohibited substancies and methods

Substances prohibited

at all times (in- and out-

of-competition)

\section{Examples of drugs and methods used for doping}

\begin{tabular}{|c|c|c|}
\hline \multirow[t]{4}{*}{ S1 } & $\begin{array}{l}\text { Anabolic agents } \\
\text { Anabolic Androgenic Steroids } \\
\text { (AAS) }\end{array}$ & \\
\hline & a) Exogenous AAS & $\begin{array}{l}\text { a) 1-androstendiol, 1-androstendione, danazol, } \\
\text { desoxymethyltestosterone, 4-hydroxytestosterone, stenbolone, } \\
\text { tetrahydrogestrinone, etc. }\end{array}$ \\
\hline & b) Endogenous AAS & $\begin{array}{l}\text { b) androstenediol, androstenedione, dihydrotestosterone, } \\
\text { testosterone, etc. }\end{array}$ \\
\hline & Other Anabolic Agents & Clenbuterol, tibolone, zeranol, zilpaterol \\
\hline S2 & Hormone and related substances & $\begin{array}{l}\text { 1. Erythropoietin (EPO) } \\
\text { 2. Growth Hormone (hGH), Insulin-like Growth Factors (e.g. IGF-1) } \\
\text { Mechano Growth Factors (MGFs) } \\
\text { 3. Gonadotrophins (LH, hCG), prohibited in males only } \\
\text { 4. Insulin } \\
\text { 5. Corticotrophins }\end{array}$ \\
\hline
\end{tabular}

S3 Beta-2 Agonists

All beta- 2 agonists including their $\mathrm{D}$ - and $\mathrm{L}$-isomers are prohibited Salbutamol, terbutaline, salmeterol and formoterol only when administered orally or by i.m.

S4 Agents with anti-estrogenic activity
1. Aromatase inhibitors
2. Selective Estrogen Receptor
2. Raloxifene, tamoxifen, toremifene Modulators (SERMs)

1. Anastrozole, letrozole, aminoglutethimide, exemestane, formestane

3. Other anti-estrogenic substances

S5 1. Diuretics

3. Clomiphene, cyclofenil, fulvestran

S

2. Other masking agents

1. Acetazolamide, amiloride, bumetanide, canrenone, chlorthalidone, etacrynic acid, furosemide, indapamide, metolazone, spironolactone, thiazides, triamterene

2. Epitestosterone, probenecid, alpha-reductase inhibitors, plasma expanders (e.g. albumin, dextran, hydroxyethil starch)

Substances prohibited

in competition

S6

Stimulants

Adrenaline (not prohibited when used by local administration or associated with local anesthetics), amphetamine, cathine (prohibited when urine concentration $>5 \mathrm{mcg} / \mathrm{ml}$ ), ephedrine and methyl ephedrine (prohibited when urine concentration $>10 \mathrm{mcg} / \mathrm{ml}$ ) etamivan, niketamide, strychnine, bupropion, caffeine, phenylephrine, phenylpropanolamine, pipradol, pseudoephedrine, synephrine are included in the 2006 monitoring program and are not considered prohibited

\begin{tabular}{lll}
\hline S7 & Narcotics & $\begin{array}{l}\text { Buprenorphine, heroin, fentanyl and derivatives, hydromorphone, } \\
\text { methadone, morphine, oxycodone, oxymorphone, pentazocine }\end{array}$ \\
\hline S8 & Cannabinoids & Hashish, marijuana \\
\hline S9 & Glucocorticosteroids & $\begin{array}{l}\text { All glucocorticoids are prohibited when administered orally, rectally, } \\
\text { i.v. or i.m. Their use requires a Therapeutic Use Exemption approval. } \\
\text { The topical forms does not require any form of exemption form }\end{array}$ \\
\hline
\end{tabular}

\section{Prohibited methods}

M1 Enhancement of oxygen transfer

a) Blood doping

a) Use of autologous, homologous or heterologous blood or red blood products

b) Artificially enhancing the uptake, b) Perfluorochemicals, efaproxiral and modified haemoglobin transport or delivery of oxygen products

M2 Chemical and physical manipulation

a) Tampering

b) Intravenous infusions

M3 Gene Doping a) Methods or manovres addressed to alter the validity of samples collected during the controls (i.e. catheterisation, urine substitution and/or alteration)

b) I.V. infusions except for acute medical treatment

The non therapeutic use of cells, genes and procedures addressed to a modulation of gene expression in order to modify a sport performance is prohibited 


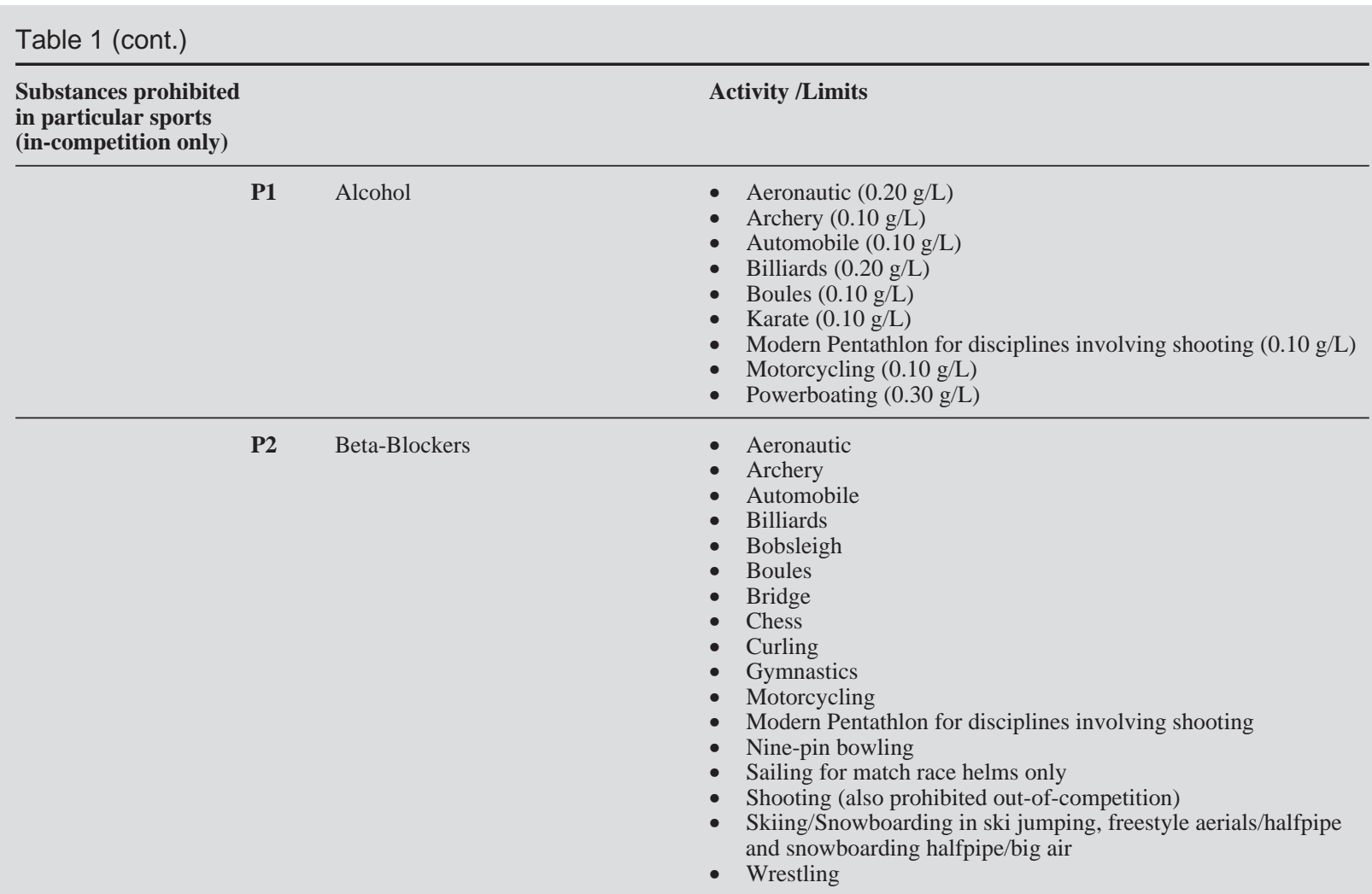

From [2] mod.

\section{S4 Agents with anti-estrogenic activity S5 Diuretics and other masking agents}

\section{Prohibited methods}

\section{M1 Enhancement of oxygen transfer:}

a) blood doping including autologous, homologous or heterologous blood or red blood cell products of any origin

b) artificially enhancing the uptake, transport or delivery of oxygen and modified haemoglobin products

\section{M2 chemical and physical manipulation M3 Gene doping}

\section{Substances and methods prohibited in a competition}

S6 stimulants (adrenaline when associated with local anaesthetic is not prohibited. Ephedrine and methylephedrine are prohibited only at a concentration greater than $10 \mathrm{mcg} / \mathrm{ml}$. Bupropion, caffeine, phenylephedrine, phenylpropanolamine, pseudoephedrine, synephrine are not considered to be "prohibited substances" included in the monitoring programme 2006)

\section{S7 Narcotics}

S8 Cannabinoids

S9 Glucocorticoids. Topical preparations when used for specific disorders (dermatological, aural, nasal, buccal cavity and ophthalmologic disorders) are not prohibited. All glucocorticoids are prohibited when administered orally, rectally, i.v. or i.m. Their use requires Therapeutic Use Exemp- tion approval. The use in Asthma requires an abbreviated Therapeutic Use Exemption.

Other substances such as alcohol and betablockers are prohibited only in some activities and we recommend consulting the special list released by the various antidoping committees.

\section{NATURAL LIMITS TO DOPING METHODS IN THE ENDURANCE PERFORMANCES}

Apart from the over-reported general rules of WADA there is a necessity to establish rigorous research in the doping area both for ethical reasons and because there is fairly good evidence regarding the uncertainty of the benefits afforded by doping [3]. Focusing the attention on the role of respiratory drugs, the first question is: can the function of the respiratory system be improved in athletes? [4]. It might be worthwhile to discuss the possible actions on the most important functional respiratory parameters. Taking the maximal oxygen consumption $\left(\mathrm{V}^{\prime} \mathrm{O}_{2}\right.$ max) as the target of most physical performances, it is known that in the high level endurance athletes, their blood saturation may decrease during heavy or extreme exercise [5-6]. A very good analysis on the possible mechanisms underlying the human aerobic performance and the limit to $\mathrm{V}^{\prime} \mathrm{O}_{2}$ was carried out by Lindstedt SL and Careley KE [7].

One of the most important goals that many prohibited substance and methods hope to achieve is to overcome the limits of $\mathrm{V}^{\prime} \mathrm{O}_{2}$ max mainly in the endurance activities. It is useful to consider the phys- 
iological moments involved in the whole process. The respiratory system is designed to allow a correct uptake of $\mathrm{O}_{2}$ according to specific demands and the authors sustain that there is not a single factor determining the $\mathrm{O}_{2}$ uptake, however any limitation imposed to $\mathrm{O}_{2}$ delivery by a single component of the respiratory system could affect $\mathrm{V}^{\prime} \mathrm{O}_{2}$ max by $10 \%$ or less. According to a traditional view that highlights the main obstacles which hamper or limit the $\mathrm{O}_{2}$ uptake the role of the conductive tubes (bronchial tree), that of the circulation, the uptake of $\mathrm{O}_{2}$ by the mitochondria should be considered. All these factors jointly or separately may participate in limiting the $\mathrm{V}^{\prime} \mathrm{O}_{2}$ max and the aerobic performances. Despite the fact that this hypothesis is rather well designed it does not seem to meet all the points that could clarify the steps involved in these limitations. With regard to doping and working with different models represented by sojourners going to high altitudes provided with additional $\mathrm{O}_{2}$ [9], natives living at high altitudes and altitude sojourners [10-11] it seems that $\mathrm{V}^{\prime} \mathrm{O}_{2}$ tracks $\mathrm{O}_{2}$ delivery but only when this step is impaired, not when the delivery is supplemented or when it is artificially enhanced. Unless there is a parallel increase in aerobic capacity of the muscles only a minimal increase in $\mathrm{V}^{\prime} \mathrm{O}_{2}$ max is gained [7].

The final lesson outlines the role of a well balanced system for supplying $\mathrm{O}_{2}$ to the mitochondria according to the locomotor costs. The structures endowed with important plasticity can show a good flexibility in relation to oxygen intake (muscle mitochondrial volume, capillary density, cardiac output and haemoglobin concentrations). In contrast non-plastic structures (trachea, lungs) must be built in such a way as to meet the different increase in lifetime oxygen demand and there is no evidence indicating a single rate-limiting step in $\mathrm{V}^{\prime} \mathrm{O}_{2}$ both in humans and in other mammals. Therefore $\mathrm{V}^{\prime} \mathrm{O}_{2} \max$ would be only one of the many factors which interact in limiting the endurance performance and all the doping systems involving hyperoxic blood doping and $\mathrm{O}_{2}$ supplementation should be of limited value.

\section{EFFECTS OF DRUGS ON RESPIRATORY SYSTEM}

Apart from the aforementioned considerations on particular forms of doping, the traditional view encompasses the use of prohibited classes of pharmacological agents and our purpose is to discuss those substances or compounds which directly or indirectly affect the respiratory system. These drugs may be used both by athletes and by normal people. We have previously reported some critical considerations regarding the possibility of overcoming the limit of $\mathrm{V}^{\prime} \mathrm{O}_{2}$ max in the endurance activity through particular methods and techniques. The conclusion was that only a modest increase in $\mathrm{V}^{\prime} \mathrm{O}_{2}$ max can be achieved. It is probable that many athletes resort to drugs to solve their problems and achieve their goals in the hope that science will provide miracles.

In the respiratory system one of the targets is represented by the possibility of prolonging the maximal sustainable ventilation, calculated as 55$88 \%$ of Maximal Voluntary Ventilation (MMV) in healthy subjects [12] for more than 15 minutes. This reduction is probably caused by muscle fatigue during a strenuous exercise [13]. One question should be addressed in respect of the possibility of training the respiratory muscles. Normally this aim can be achieved in normal sedentary people with an increase of their endurance [14] capacity at $62-75 \%$ of $\mathrm{V}^{\prime} \mathrm{O}_{2} \max$.

The same goal is not completely proved in healthy athletes, normally well organically conditioned even if it has been hypothesised that an additional training of respiratory muscles can improve the breathing endurance in cyclists [15].

In well trained normal subjects this improvement demonstrated in respiratory muscles allows an increase in cycle endurance at the anaerobic threshold [16]. These observations reflect the necessity of training respiratory muscles both in the athletes, in normal subjects and in respiratory patients.

It is not possible to separate exactly the role played by many substances on the respiratory system from actions addressed to meet other targets in completing the sport activity, however the results strictly limited to the respiratory system seem variable and not easily reproducible when evaluated on a normal and well trained population.

\section{LIST OF THE MOST QUOTED SUBSTANCES AND THEIR MAIN EFFECTS}

Erythropoietin: we have already outlined the limited role exerted by an $\mathrm{O}_{2}$ support in normal non- extreme situations and by autologous and homologous transfusions on the $\mathrm{V}^{\prime} \mathrm{O}_{2}$ max during endurance activities. In the case of transfusion, the athletes have experienced very complex adaptations such as an increase in red cell mass and an unwanted decrease in haemoglobin concentration deriving from a considerable increase in plasma volume as a side effect of the transfusional procedures. The availability of synthetic erythropoietin ( $\mathrm{r}-\mathrm{Hu}$ EPO) replaced transfusion as a blood doping.

Erythropoietin caused an increase in haemoglobin levels and of physical performances in young males who received $\mathrm{r}-\mathrm{Hu}$ EPO for seven weeks [17]. This substance improves aerobic performances and this fact suggests a wide misuse in many sporting activities. The companion use of plasma expander masks the increase of the haematocrit. One of the main risks is the possibilities of eliciting thrombosis when the blood viscosity is markedly increased.

Stimulants: Amphetamines are potent sympathicomimetic amines. They stimulate the respiratory centre, increase arousal and can improve pulmonary ventilation [18]. These substances bind to alpha and beta receptors promoting, as a net result, an increase of blood pressure, heart rate and metabolic rate. Through the catecholamine release amphetamines increase the plasma Free Fatty Acid 
(FFA) causing a sparing effect on the glycogen of the muscular fibres and a delay in the onset of fatigue [19-20].

However, it is difficult to demonstrate an improvement of exercise performance only due to the action on respiratory system. Very interesting experiments carried-out in non professional athletes proved that the administration of amphetamines can improve muscular strength, sprint performances and anaerobic capacity [21].

Caffeine: Caffeine is a methylated xanthine alkaloid derivative (1,3,7-trimethylxanthine) normally present in many beverages and its misuse as a stimulant in sportsmen has been very popular over the years.

Its mechanism of action includes the inhibition of phosphodiesterase with a consequent intracellular increase of cAMP and an alteration of calcium translocation via the ryanodine receptors [4]. The concentration of caffeine necessary to elicit this calcium release is high but it has been demonstrated that cyclic ADP-ribose can affect the action of caffeine on the induced calcium release and it follows that physiological doses of caffeine also could alter calcium availability via ryanodine receptors. This would happen at the level of respiratory and of skeletal muscles through the process of excitation-contraction coupling [22]. At higher doses caffeine blocks adenosine receptors and, like all methylxanthines, support a stimulant action on CNS as well as diuretic, metabolic and cardiac effects.

Caffeine provokes an increase of ventilation at rest with a consequent decrease of the $\mathrm{PCO}_{2}$ levels caused by an increased output from the respiratory centre [23]. Moreover caffeine enhances the metabolic rate as demonstrated by increases of $\mathrm{V}^{\prime} \mathrm{O}_{2}$ and $\mathrm{V}^{\prime} \mathrm{CO}_{2}$ at rest. Caffeine can also prolong the endurance time and at the same time reduce the perception of fatigue during resistive breathing [24]. This last event is confirmed by lower levels of plasma $\mathrm{K}+$ concentration with a subsequent potential increase of force generation in skeletal muscles and a possible delay of fatigue both at respiratory level and at that of skeletal muscles [25-26]. The net result could be an artificial improvement of physical performances.

Under the metabolic prophile caffeine provides important effects: an increase in fat mobilisation and a spare of muscle glycogen during exercise. The glycogen sparing effect has been particularly evident at $65-70 \%$ of $\mathrm{V}^{\prime} \mathrm{O}_{2}$ max when the glycogen depletion provokes an important sensation of fatigue [27]. The caffeine can also spare both lactate and glycogen during short term exercises [28]. However, it is doubtful that caffeine can, by itself, enhance the respiratory muscles function and their endurance only on the basis of glycogen spare. Despite all the experimental data there is no univocal opinion on the role of caffeine which could not affect the maximal performances of high level athletes [29]. On the contrary caffeine ingestion caused a significant improvement on the increase of endurance in two short term exercises at the cycle-ergometer in comparison with placebos in recreationally trained athletes [28].

In conclusion caffeine seems to be an old drug that can support small but important effects and therefore, when administered at high doses, may induce artificial results.

Beta-2-adrenergic drugs: Before facing the problem of beta2 adrenergic drugs it is worthwhile mentioning the role of other non-selective sympathicomimetic drugs mainly used in the past.

Phenylpropanolamine and ephedrine share a structure related to amphetamine. The first compound is used as a remedy for nasal congestion. Both are stimulants of CNS (ephedrine more than Phenylpropanolamine) and share direct and indirect effects on adrenergic receptors betal and beta2. Ephedrine is also an alfa and beta adrenergic agonist, stimulates the release of noradrenaline from sympathetic neurones, promotes a bronchodilating action and, as already quoted, is a potent CNS stimulant [30]. However, in controlled studies ephedrine (1 mg/Kg or $60-120 \mathrm{mg})$ did not succeed in affecting ventilation at rest or during exhaustive exercise at cycle ergometry and in shortening the time to reach $85 \%$ of predicted maximum heart rate [31-32].

Selective beta2 agonists like salbutamol, terbutaline, formoterol and salmeterol are widely used in the treatment of asthma and their use is allowed in the sport activities only if administered by topic aerosol [2]. The animal model can depict in a more specific way the many targets, apart from bronchial muscles, of these substances. Clenbuterol is a member of this group licensed in the European community for therapeutic use in food producing species [33]. These authors stress the fact that beta 2 agonists drugs, particularly clenbuterol, stimulate the growth promotion with important effects in the partitioning of lean and fat tissues in favour of the lean parts. Moreover changes in morphological, histological and biochemical features of animal treated with clenbuterol have been observed. A rapid hypertrophy of skeletal muscles and of nitrogen retention seems to be elicited by a slower decrease on protein degradation.

In the fat tissue a general reduction of body fat tissue was observed explained by an enhancement of lipolysis, inhibition of lipogenesis, enhancement of fatty acid turnover and oxidation, decrease of preadipocyte recruitment and reduction of the size of fat cells.

The endocrine system is affected by a regulation of Insulin secretion or by increasing the blood flow to peripherical tissue. These parts may increase the metabolic rate and positively change the capacity for $\mathrm{O}_{2}$ and the uptake of glucose, amminoacid, non-esterified fatty acids and protein accretion.

Also in humans beta2 agonists, when administered orally, intravenously or intramuscularly, may increase skeletal muscle mass or their force depending on the dose and on the duration of treatment [34-35]. Ventilatory endurance and $\mathrm{Pi}_{\max }$ 
were also increased after salbutamol treatment [35]. On the contrary some experiments failed in demonstrating that inhalation of salbutamol or salmeterol can improve the performances of healthy or asthmatic athletes [36-37-38] at therapeutic doses. Other experiments also showed that intravenously salbutamol could not improve exercise tolerance in asthmatic athletes [39]. Conversely asthma has a very high prevalence in athletes: from $3.7 \%$ up to $22.8 \%$ in the systemic review of Helenius I and Haahtela T [40]. The risk of asthma seems to be significantly higher in athletes than in the normal population particularly when there is a combination of atopy and exercise as it has been demonstrated in atopic swimmers [41].

In the past some compounds, i.e. formoterol, were initially excluded from a possible administration among competitive athletes. However it has been demonstrated that formoterol, like other short-acting and long-acting compounds, in a double blind placebo-controlled study when 24 healthy well trained competitive athletes were enrolled, did not improve any parameter of endurance performance [42)].

Lung function on the contrary improved significantly after inhaled formoterol but showed no difference between formoterol and placebo after exercise. These results should prove that when beta2 agonists are administered by aerosol, at the suggested therapeutic doses, they do not affect the physical performances.

A good technical procedure should be recommended for the screening of samples taken from the athletes for control [43]. In this way it should be easy to discriminate the users with real health problems from those we might defined as "doped". The first model of study might be represented by winter sport athletes during their endurance applications. As previously reported the occurrence of asthma in this field is frequent [44] but these authors conclude that the frequency of anti-asthmat- ic medication is lower in the Finnish Olympic athletes than in the general population when a diagnosis of asthma has been set by a physician.

Looking not only at the doping problem but also at the professional work of all the pneumologists it has been to be recommended the feasibility of proper tests in order to demonstrate the presence both of an Exercise Induced Asthma and a true reversible bronchospasm or bronchoconstriction [45] especially in the high level athletes. The uncertainty arising from a lack of a univocal percentage of $\mathrm{FEV}_{1}$ decrease in different situation $(10 \%$ for EIA/B and $20 \%$ for methacoline) renders unclear why a change of $\mathrm{FEV}_{1}$ is a real sign of EIB, while it is insignificant for bronchial hyperactivity. Moreover methacoline may be considered the test of choice in the world to detect the presence of a hyperreactivity. This leads to a common wish to avoid the risk, on behalf of sport's rules, of an inadequate management of asthma [46].

This last assumption does not contrast with the illegal use of clenbuterol not only on the basis of the previous considerations but also for its specific action on myofibrillar protein concentration and on a slow to fast shift in the myosin heavy chain (MHC) pool both in the leg muscle and in the diaphragm [47-48]. However this last observation might prove useful in some rehabilitative programmes but it is definitely not admitted as a support in sport activities.

The use of clembuterol as anabolic drug exposes the users also to severe risk of myocardial infarction even in a young age [49] and abuse of this substance can provoke very serious damage.

Table 2 includes the permitted respiratory drugs according to the current rules.

Anabolic Steroids: These substances might affect the respiratory muscles activity promoting incorporation of amino acids into muscle proteins, reducing aminoacid catabolism and supporting ni-

Table 2. - Permitted respiratory drugs

\begin{tabular}{lll}
\hline Category & Drug & Route of administration \\
\hline$\beta_{2}$-stimulants & Salbutamol & MDI \\
& Terbutaline & MDI \\
& Formoterol & MDI \\
& Salmeterol & MDI \\
\hline Theophylline & - & All the routes \\
\hline Atropine derivatives & Ipratropium brom. & MDI \\
& Oxytropium brom. & MDI \\
\hline Cromones & Thiotropium brom. & Powder \\
\hline Antileukotriens & Nedocromile sodium & No limitations \\
\hline
\end{tabular}

From [2] mod. 
trogen retention and tissue growth [50]. These fact might cause an increase of muscle performance.

With regard to the function of diaphragm, an increase of the force and a shortening in the velocity of the muscular fibres in the rat has been demonstrated [51]. In practice apart from the action on skeletal muscles, no significant and reproducible action has been shown on diaphragm and on aerobic capacity [4].

Human growth hormone (hGH): This growth hormone or somatotropine stimulates protein synthesis and inhibits glucose utilisation via an increase of lipolysis. Of course it promotes tissue growth with a nitrogen retention and increases the transport of aminoacids in the tissues [52].

Apart from many known/unknown actions on the limb muscles, a clear and selective effort on respiratory muscles has not been reported.

\section{EXERCISE INDUCED ASTHMA (E.I.A) OR EXERCISE INDUCED BRONCHOCONSTRIC- TION (E.I.B.)}

The term E.I.A./E.I.B describes an acute and transient airway narrowing that occurs after exercise in $10-50 \%$ of elite athletes according to their physical activity and to the specificity of a single sport [53]. This kind of bronchoconstriction also affects $80-90 \%$ of individuals with asthma and approximately $11 \%$ of the general population without asthma [54]. E.I.B. is also frequent among children and adolescents and has been reported most often in athletes active in endurance sports and amongst those competing in cold climates, i.e. cross-country skiers [55] or swimmers [57]. The most common method of testing E.I.B. is to ask the patient to run for 6-8 min on a flat surface with a temperature of $20{ }^{\circ} \mathrm{C}$ and a relative humidity of $\sim 40 \%$ in order to achieve his/her maximal heart rate. Alternatively a treadmill or a cycloergometer may be used. The pulmonary function is evaluated by spirometry before the beginning of the exercise, immediately after its cessation and ' ', 6', 10', 15' and 20' later. $\mathrm{FEV}_{1}$ is the parameter usually employed and a fall of $10 \%$ is considered a sign of E.I.B. The recognition of an E.I.B. and its demonstration through a significative fall of $\mathrm{FEV}_{1}$ after a standardised exercise is also considered a sign of aspecific bronchial hyperactivity. When adding extraordinary stimules like running on treadmill with an inhalation of dry cold air $\left(-20^{\circ}\right)$, the sensitivity of this test is strongly increased and its specificity is also increased [58].

Other situations such as an exercise-induced laryngeal inspiratory stridor or an excessive hyperventilation are to keep in mind as possible differential diagnosis. Important inspiratory stridors during maximal exercise are typical among well trained female athletes. However in contrast to E.I.B. this finding is evidenced during the exercise and not after. In these cases therapy is quite useless.

\section{Pathogenesis of E.I.B.}

A review of the literature allows to summarise the most quoted theories on this point [59]: 1) hy- perosmolar theory and 2) the airway rewarming theory. Moreover airway inflammation is present as an adjunctive element in some elite athletes mainly, among those exerting their activity at low temperatures. However, nowadays the main factor causing a mediator release which provokes bronchospasm is considered to be the change in osmolarity of the periciliar fluid lining the surface of the respiratory epithelium sustained both by a heat loss and by a water loss from the bronchial tree. In any case the increase in chlorine ions on the surface of epithelium might be the principal stimules for a mediator release [60]. The chain of events leading to the final bronchoconstriction is represented in fig. 1.

\section{Treatment of E.I.B}

Prophylactic treatment: Anti-inflammatory treatment is especially recommended for treatment of asthma and E.I.B.. In this field inhaled steroids are the most important resource, well indicated for regular therapy of asthma according to the current guidelines [61].

The use of a leukotriene receptor antagonist like montelukast induces important results in attenuating E.I.B. after 2 days of treatment in adults and children [62]. In addition disodium cromoglycate (DSCG) and nedocromile sodium proved in the past to have fairly good efficacy in decreasing the obstructive response to the exercise.

Treatment before exercise: The most usual drugs assumed in the pre-treatment of E.I.B. are $\beta_{2}$-agonists [54]. Taken 15 minutes before the ex-

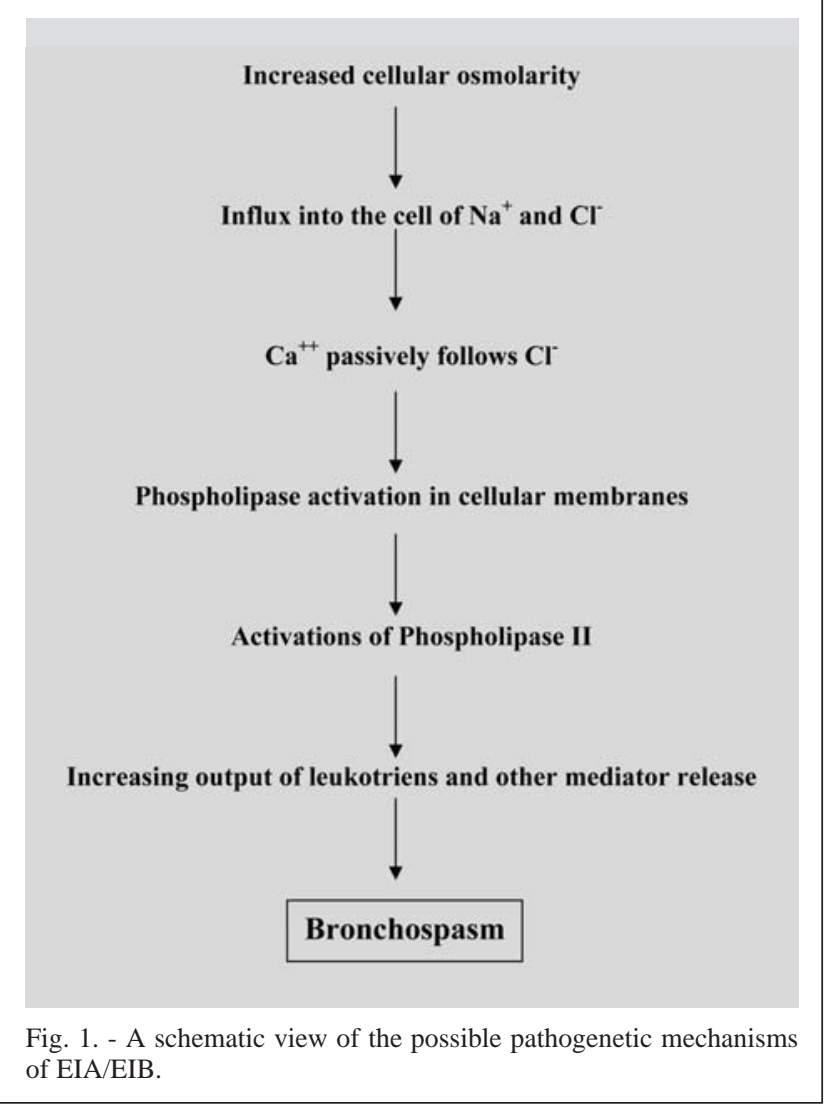


ercise these compounds reduce the fall of the lung function and protect the athletes for some hours.

Salbutamol and terbutaline are the most experienced drugs, but also inhaled formoterol and salbutamol protects against E.I.B. for a more extended period in comparison to salbutamol and terbutaline according to their chemical structure and their pharmacodynamic features. Montelukast exerts a long and efficient protection capable to be extended to 24 hours.

\section{E.I.B. and Doping}

Correct, although frequent, use of bronchodynamic drugs arises the suspicion of an illicit abuse of some category of compounds, specifically $\beta_{2}$-agonists. Moreover a recurrent question regards the possibility of enhancing the athletic performances under the use of these drugs. It has been well demonstrated that only clenbuterol in animals and man can cause an increase of muscle mass. This drug is strictly prohibited, but other $\beta_{2}$-stimulants and steroids administered topically are allowed in asthmatic athletes, also in that small percentage of sportmen/women complaining an E.I.B. alone. Apart from salbutamol and terbutaline also salmeterol and formoterol, when assumed at therapeutic doses and topically, proved to be uninfluent on the sports performances [63].

The use of antileukotriens administered orally is permitted because no adjunctive effect on physical performances has been demonstrated.

According to the last statement of WADA [2] the use of $\beta_{2}$-stimulants and steroids, although administered topically, must be declared by the athletes prior to participation in the sports activity by completing a precise application form.

\section{PROCEDURE TO DIFFERENTIATE THE} ILLICIT USE OF DRUGS AND SUBSTANCES

Referring a complete treatment of this subject to specific publications and guidelines, we should remember that WADA recommends, as a priority, the efficiency of the labs involved in the reference network, according to the results of proficiency procedures.

Looking at respiratory system three principal fields of interest should be mentioned:

a) Blood doping;

b) Steroids;

c) $\beta_{2}$-stimulants;

a) a very simple method commonly used in many sports is the control of the hematocrit before a competition or during a training session. Of course many other factors have to be taken into account (i.e. the altitude, the temperature, the perspiration etc);

b) much more difficult is the detection of steroids because the development of synthetic compounds with the same structure as the natural steroids provoking confusion due to the potential overlap. A new technology based on "Isotope Ratio Mass Spectrometry (IRMS)" included in the project Isotrace should allow the detection of specific isotopes contents of prohibited synthetic hormones. Another project identified as SGLC/MS is addressed to the develop of a new Liquid Chromatography Mass Spectrometry (LC/MS) for a rapid detection Anabolic Androgenic Steroids (AAS). A new direction followed by the accreditated laboratories is represented by the development of very refined methods capable to detect certain anabolic steroids at very low threshold values ( $2 \mathrm{ng} / \mathrm{mL}$ or lower) employing a high resolution mass spectrometry (HRMS) or tandem mass spectrometry (MS/MS) more sensitive than conventional mass spectrometry. These methods have been validated and improved so that the screening of steroids at low levels can be performed in IOC/WADA labs. An adjunctive advantage of these sensitive methods is represented by the possibility of identifying the abuse of steroids for more weeks than was possible before;

c) two conventional screening procedures gas chromatography/mass spectrometry (GC/MS) and ELISA an analytical procedure for detection of stimulants, narcotics, beta-blockers, beta-agonists and many of their metabolites in urine are sensitive enough to detect an abuse of these substances specially when administered orally. A GC/MS system is sensitive and specific to detect and identify approximately 100 compounds and metabolites in urine for at least 24 hours after administration of therapeutic doses.

For a more detailed treatment of these and other subjects regarding doping the reader can consult the following references $[64,65,66]$ on-line.

\section{Conclusions}

Doping procedures must be considered globally for ethical reasons and for important questions of health. In this short overview we mainly endeavoured to focus the effects of different categories of drugs, methods and techniques on the respiratory system. However, just owing to the first assumption, it is very difficult to separate what must be strictly concentrated on the respiratory system from more general and wider reflexes involving other systems and organs.

In addition in the respiratory field it is not clear whether a result is attained through an improvement in the area of respiratory centres or in that of respiratory muscles or simply decreasing the fatigue during an endurance performance. Another important goal traced back to the area of doping is represented by masking the sense of fatigue, an important determinant of improved performances.

Apart from the different pharmacological actions exhibited by many substances, an important point is represented by the addiction that makes doping similar to an abuse of other major substances.

These considerations pledge to be severe in punishing cheats and anyone responsible for providing and using doping substances. However the sports medicine specialists and pneumologists must be aware of distinguishing the athletes who 
really need a correct diagnosis of asthma or of exercise induced bronchospasm and a well balanced treatment from those who fraudulently abuse prohibited substances.

\section{References}

1. I.O.C. FACT SHEET. The fight against doping and promotion of athletes' healt. Dec 2005 1/5

2. World Antidoping Agency. The 2006 prohibited list. International standards. WADA Ed. Sept. 2005.

3. Kennedy MC. Newer drugs used to enhance sporting performance. Med J Aust 2000; 173: 314-7.

4. Dekhuijzen PN, Machiels HA, Heunks LM, van der Heijden HF, van Balkom RH. Athletes and doping: effects of drugs on the respiratory system. Thorax 1999; 54: 1041-6.

5. Dempsey JA, Hanson PG, Henderson KS. Exercise-induced arterial hypoxaemia in healthy human subjects at sea level. J Physiol 1984; 355: 161-75.

6. Williams JH, Powers SK, Stuart MK. Hemoglobin desaturation in highly trained athletes during heavy exercise. Med Sci Sports Exerc 1986: 18: 168-73.

7. Lindstedt SL, Conley KE. Human aerobic performance: too much ado about limits to $\mathrm{V}^{\prime} \mathrm{O}_{2}$. J Exp Biol 2001; 204: 3195-9.

8. Ferretti G, di Prampero PE. Factors limiting maximal $\mathrm{O}_{2}$ consumption: effects of acute changes in ventilation. Respir Physiol 1995; 99: 259-71.

9. Spriet LL, Gledhill N, Froese AB, Wilkes DL. Effect of graded erythrocythemia on cardiovascular and metabolic responses to exercise. J Appl Physiol 1986; 61: 1942-8.

10. Cymerman A, Reeves JT, Sutton JR, et al. Operation Everest II: maximal oxygen uptake at extreme altitude. J Appl Physiol 1989; 66: 2446-53.

11. Favier R, Spielvogel H, Desplanches D, Ferretti G, Kayser B, Hoppeler H. Maximal exercise performance in chronic hypoxia and acute normoxia in high-altitude natives. J Appl Physiol 1995; 78: 1868-74.

12. Leith DE, Bradley M. Ventilatory muscle strength and endurance training. J Appl Physiol 1976; 41: 508-16.

13. Bye PT, Farkas GA, Roussos C. Respiratory factors limiting exercise. Annu Rev Physiol 1983; 45: 439-51.

14. Boutellier U, Piwko P. The respiratory system as an exercise limiting factor in normal sedentary subjects. Eur J Appl Physiol Occup Physiol 1992; 64: 145-52.

15. Fairbarn MS, Coutts KC, Pardy RL, McKenzie DC. Improved respiratory muscle endurance of highly trained cyclists and the effects on maximal exercise performance. Int J Sports Med 1991; 12: 66-70.

16. Boutellier U, Buchel R, Kundert A, Spengler C. The respiratory system as an exercise limiting factor in normal trained subjects. Eur J Appl Physiol Occup Physiol 1992; 65: 347-53.

17. Ekblom B. Blood doping and erythropoietin. The effects of variation in hemoglobin concentration and other related factors on physical performance. Am J Sports Med 1996; 24 (6 Suppl): S40-2.

18. Folgering H. Studying the control of breathing in man. Eur Respir J 1988; 1: 651-60.

19. Pinter EJ, Patee CJ. Fat-mobilizing action of amphetamine. J Clin Invest 1968; 47: 394-402.

20. Clarkson PM, Thompson HS. Drugs and sport. Research findings and limitations. Sports Med 1997; 24: 366-84.

21. Chandler JV, Blair SN. The effect of amphetamines on selected physiological components related to athletic success. Med Sci Sports Exerc 1980; 12: 65-9.

22. Dollery C. Therapeutic Drugs. Edimburgh: Churchill and Livingstone 1999.
23. D'Urzo AD, Jhirad R, Jenne H, et al. Effect of caffeine on ventilatory responses to hypercapnia, hypoxia, and exercise in humans. J Appl Physiol 1990; 68: 322-8.

24. Supinski GS, Levin S, Kelsen SG. Caffeine effect on respiratory muscle endurance and sense of effort during loaded breathing. J Appl Physiol 1986; 60: 2040-7.

25. Lindinger MI, Graham TE, Spriet LL. Caffeine attenuates the exercise-induced increase in plasma $[\mathrm{K}+]$ in humans. J Appl Physiol 1993; 74: 1149-55.

26. Cairns SP, Hing WA, Slack JR, Mills RG, Loiselle DS Different effects of raised $[\mathrm{K}+]$ o on membrane potential and contraction in mouse fast- and slow-twitch muscle. Am J Physiol 1997; 273 (2 Pt 1): C598-611.

27. Hultman E. Nutritional effects on work performance. Am J Clin Nutr. 1989; 49 (5 Suppl): 949-57.

28. Jackman M, Wendling P, Friars D, Graham TE. Metabolic catecholamine, and endurance responses to caffeine during intense exercise. J Appl Physiol 1996; 81: 1658-63.

29. Wemple RD, Lamb DR, McKeever KH. Caffeine vs caffeine-free sports drinks: effects on urine production at rest and during prolonged exercise. Int J Sports Med 1997; 18: 40-6

30. Hoffman BB, Lefkowitz RJ. Catecolamine, sympathicomimetic drugs and adrenergic receptor antagonists. In: Handman JG, Lambird LE eds. The pharmacological basis of Therapeutics. New York, Mc GrawHill 1996; 199-237.

31. Bell DG, Jacobs I, Zamecnik J. Effects of caffeine, ephedrine and their combination on time to exhaustion during high-intensity exercise. Eur J Appl Physiol Occup Physiol 1998; 77: 427-33.

32. Bright TP, Sandage BW Jr, Fletcher HP. Selected cardiac and metabolic responses to pseudoephedrine with exercise. J Clin Pharmacol 1981; 21: 488-92.

33. Prezelj A, Obreza A, Pecar S. Abuse of clenbuterol and its detection. Curr Med Chem 2003; 10: 281-90.

34. Caruso JF, Signorile JF, Perry AC, et al. The effects of albuterol and isokinetic exercise on the quadriceps muscle group. Med Sci Sports Exerc 1995; 27: 1471-6.

35. Martineau L, Horan MA, Rothwell NJ, Little RA. Salbutamol, a beta 2-adrenoceptor agonist, increases skeletal muscle strength in young men. Clin Sci (Lond) 1992; 83: 615-21.

36. Freeman W, Packe GE, Cayton RM. Effect of nebulised salbutamol on maximal exercise performance in men with mild asthma. Thorax 1989; 44: 942-7.

37. Norris SR, Petersen SR, Jones RL. The effect of salbutamol on performance in endurance cyclists. Eur J Appl Physiol Occup Physiol 1996; 73: 364-8.

38. Violante B, Pellegrino R, Vinay C, Selleri R, Ghinamo G. Failure of aminophylline and salbutamol to improve respiratory muscle function and exercise tolerance in healthy humans. Respiration 1989; 55: 227-36.

39. Malerba M, Boni E, Tantucci C, Filippi B, Romagnoni $\mathrm{G}$, Grassi V. Ineffectiveness of intravenous beta 2-agonists on improving exercise tolerance in patients with reversible chronic airway obstruction. Respiration 1996; 63: 8-16.

40. Helenius I, Haahtela T. Allergy and asthma in elite summer sport athletes. J Allergy Clin Immunol 2000; 106: 444-52.

41. Helenius IJ, Tikkanen HO, Sarna S, Haahtela T. Asthma and increased bronchial responsiveness in elite athletes: atopy and sport event as risk factors. $J$ Allergy Clin Immunol 1998; 101: 646-52.

42. Carlsen KH, Hem E, Stensrud T, Held T, Herland K, Mowinckel P. Can asthma treatment in sports be doping? The effect of the rapid onset, long-acting inhaled beta2-agonist formoterol upon endurance performance in healthy well-trained athletes. Respir Med 2001; 95: 571-6. 
43. Berges R, Segura J, Ventura R, et al. Discrimination of prohibited oral use of salbutamol from authorized inhaled asthma treatment. Clin Chem 2000; 46: 1365-75.

44. Alaranta A, Alaranta H, Palmu P, et al. Asthma medication in Finnish olympic athletes: no signs of inhaled beta2agonist overuse. Med Sci Sports Exerc 2004; 36: 919-24.

45. Anderson SD, Fitch K, Perry CP, et al. Responses to bronchial challenge submitted for approval to use inhaled beta2-agonists before an event at the 2002 Winter Olympics. J Allergy Clin Immunol 2003; 111: 45-50.

46. Bonini S, Brusasco V, Carlsen KH, et al. Diagnosis of asthma and permitted use of inhaled beta2-agonists in athletes. Allergy 2004; 59: 33-6.

47. Lynch GS, Hayes A, Campbell SP, Williams DA. Effects of beta 2-agonist administration and exercise on contractile activation of skeletal muscle fibers. J Appl Physiol 1996; 81: 1610-8.

48. Smith WN, Dirks A, Sugiura T, Muller S, Scarpace P, Powers SK. Alteration of contractile force and mass in the senescent diaphragm with beta(2)-agonist treatment. J Appl Physiol 2002; 92: 941-8.

49. Kierzkowska B, Stanczyk J, Kasprzak D. Myocardial infarction in a 17-year-old body builder using clenbuterol. Circ Journ 2005; 69: 1144-1146.

50. Haupt HA, Rovere GD. Anabolic steroids: a review of the literature. Am J Sports Med 1984; 12: 469-84.

51. Lewis MI, Fournier M, Yeh AY, Micevych PE, Sieck GC. Alterations in diaphragm contractility after nandrolone administration: an analysis of potential mechanisms. J Appl Physiol 1999; 86: 985-92.

52. Clarkson PM, Thompson HS. Drugs and sport. Research findings and limitations. Sports Med 1997; 24: 366-84.

53. Rundell KW, Jenkinson DM. Exercise induced bronchospasm in the elite athletes. Sports Med 2002; 32: 583-600.

54. Gotshall RW. Exercise induced bronchocostriction. Drugs 2002; 62: 1725-39.
55. Heir T, Oseid S. Self-reported asthma and exercise induced asthma symptoms in high level competitive cross-country skiers. Scand Med Sci Sports 1994; 4: 128-33.

56. Larsson K, Oblsen P, Larsson L, Malmberg P, Rydstrom PO, Ulriksen H. High prevalence of asthma in cross-country skiers. BMJ 1993; 307: 1326-29.

57. Helenius IJ, Rytila P, Metso T, Haahtela T, Venge P, Tikkanem HO. Respiratory symptoms, bronchial responsiveness and cellular characteristics of induced sputum in elite swimmers. Allergy 1998; 53: 346-52.

58. Carlsen KH, Engh G, Mork M, Schroeder E. Could air inhalation and exercise-induced bronchocostriction in relationship to methacoline bronchial responsiveness - Different patterns in asthmatic children and children with other chronic lung disease. Resp Med 1998; 92: 308-15.

59. Storms WW. Review of exercise-induced asthma. Med Sci Sports Exerc 2003; 35: 1464-70.

60. Anderson SD, Daviskas E. The airway microvasculature and exercise induced asthma. Thorax 1992; 47: 748-52.

61. GINA - Report Global strategy for Asthma Management and Prevention - November 2006 http: //www. ginasthma.com.

62. Left JA, Busse WW, Pearlman D, Bronski E, Kempi J, Hendeles L, et al. Montelukast a leukotriene-receptor antagonist, for the treatment of mild asthma and exercise- induced bronchocostriction. N Engl J Med 1998; 339: 147-152.

63. World Anti Doping Agency (WADA) Anti-doping documentation http: //www.wada-ama.org.

64. Dean R Hinitz, Charles E Yesalis, Michael S. Bahrke. Performance-Enhancing Substances in Sport and Exercise - 2006 HumanKinetics.com on-line ed.

65. European Commission- General Directorate XII- Science, Research and Development- Final Project report SMT4-CT98-6530. Harmonisation of Methods and Measurements in the Fight against doping (HARDOP) http: //ec.europa.eu/research/smt/hardop-en.pdf

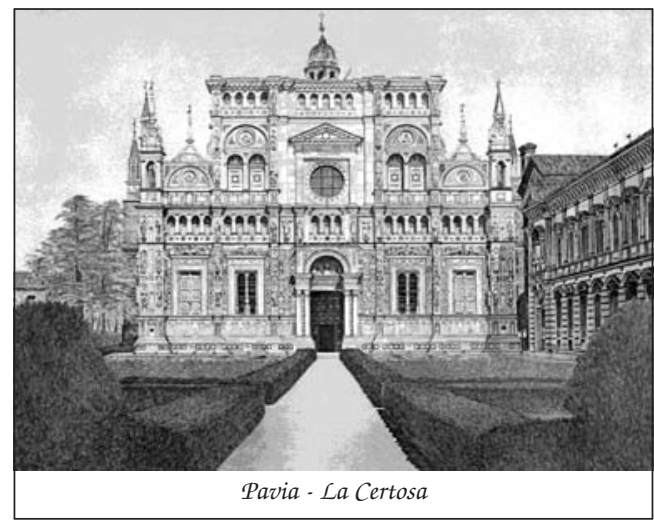

